\title{
Hybrid Integration of Taguchi Parametric Design, Grey Relational Analysis, and Principal Component Analysis Optimization for Plastic Gear Production
}

\author{
Nik Mizamzul Mehat, ${ }^{1,2}$ Shahrul Kamaruddin, ${ }^{2}$ and Abdul Rahim Othman ${ }^{2}$ \\ ${ }^{1}$ Department of Mould Technology, Kolej Kemahiran Tinggi MARA, Balik Pulau, Genting, 11000 Balik Pulau, Penang, Malaysia \\ ${ }^{2}$ School of Mechanical Engineering, Universiti Sains Malaysia, Engineering Campus, 14300 Nibong Tebal, Penang, Malaysia \\ Correspondence should be addressed to Nik Mizamzul Mehat; nik_miza78@yahoo.com
}

Received 27 September 2013; Accepted 17 November 2013; Published 14 January 2014

Academic Editors: M. Chen, C. Del Gaudio, H. Lu, S. Simani, and B. Sun

Copyright ( 2014 Nik Mizamzul Mehat et al. This is an open access article distributed under the Creative Commons Attribution License, which permits unrestricted use, distribution, and reproduction in any medium, provided the original work is properly cited.

\begin{abstract}
The identification of optimal processing parameters is an important practice in the plastic injection moulding industry because of the significant effect of such parameters on plastic part quality and cost. However, the optimization design of injection moulding process parameters can be difficult because more than one quality characteristic is used in the evaluation. This study systematically develops a hybrid optimization method for multiple quality characteristics by integrating the Taguchi parameter design, grey relational analysis, and principal component analysis. A plastic gear is used to demonstrate the efficiency and validity of the proposed hybrid optimization method in controlling all influential injection moulding processing parameters during plastic gear manufacturing. To minimize the shrinkage behaviour in tooth thickness, addendum circle, and dedendum circle of moulded gear, the optimal combination of different process parameters is determined. The case study demonstrates that the proposed optimization method can produce plastic-moulded gear with minimum shrinkage behaviour of $1.8 \%, 1.53 \%$, and $2.42 \%$ in tooth thickness, addendum circle, and dedendum circle, respectively; these values are less than the values in the main experiment. Therefore, shrinkage-related defects that lead to severe failure in plastic gears can be effectively minimized while satisfying the demand of the global plastic gear industry.
\end{abstract}

\section{Introduction}

Injection moulding is a complex process because of its requirements for numerous delicate adjustments. The quality of an injection-moulded part significantly depends on the selection of appropriate materials, parts, mould designs, and processing parameters. A review of previous works shows that the setting of processing parameters significantly affects the quality of plastic parts $[1,2]$. The selection of injection moulding process parameters previously involves a trial-and-error method [3]. However, obtaining an optimal parameter setting for complex-manufacturing processes is difficult because the trial-and-error method is a "one change at a time" test [4]. This tuning exercise is repeated until the quality of the moulded part is found satisfactory, thus incurring high production costs and long setup times [5]. Moreover, the adjustments and modifications of processing parameters rely heavily on the experience and intuition of the moulding personnel [6]. Nevertheless, the growing demand in the industry for expert moulding personnel exceeds the supply; moreover, amateur moulding personnel require more than 10 years of experience to be considered experts [7].

In a fiercely competitive market, the trial-and-error approach cannot meet the challenges of globalization, particularly at the point where the disadvantages outweigh the advantages. Thus, the interest in substituting the trial-anderror method with a fast and reliable optimization approach such as the Taguchi method continues to increase. The Taguchi method considerably reduces the time and effort needed to obtain optimal process conditions and to determine the important factors that affect plastic part quality. The application of the Taguchi method has attracted considerable attention in the literature over the past 20 years and has been widely applied to various fields, such as manufacturing 
systems [8], mechanical component design [9], and parameter optimization [10, 11]. Li et al. [12] exploited the Taguchi method to eliminate the weld line of the right door of a copy machine by optimizing the melt temperature, injection speed, and injection pressure. Wu and Liang [13] further improved the weld line strength of an injection-moulded part by optimizing the mould temperature, packing pressure, injection acceleration, and packing time. By focusing on warpage in the thin-walled plastic part, many researchers used the experimental design of the Taguchi method to optimize the injection moulding parameters; packing pressure was found to be the most influential factor on the warpage problem [14-16]. Oktem et al. [17] improved the shrinkage and warpage in a plastic part by approximately $2.17 \%$ and $0.7 \%$, respectively, by determining the optimal packing time, packing pressure, injection time, and cooling time by using the Taguchi method.

A number of studies have shown that the Taguchi method is a robust experimental design for obtaining the best combination of factors or levels with the lowest cost solution to achieve the quality requirements of plastic parts. Nevertheless, the Taguchi method exhibits a number of limitations. The optimization design of injection moulding process parameters can be difficult because more than one quality characteristic is used in the evaluation. Problems arise when the optimal process parameters contradict one another because of different mechanisms [18]. To address this problem, many studies devised new experiment design methodologies that optimize multiple quality characteristics simultaneously while providing accurate results by integrating the Taguchi method with other techniques. One such technique is grey relational analysis (GRA). This technique was first proposed by Deng [19] to optimize the multiresponse problem by using the grey relational coefficient and grey relational grade. The grey relational coefficient can express the relationship between the desired and actual experiment results, whereas the grey relational grade is simultaneously computed to correspond to each quality characteristic.

Few works have studied the optimization of injection moulding process parameters by using the integration of Taguchi method and GRA. Fung [20] adopted the integration method to improve the wear volume losses in both the parallel and perpendicular directions and inspected the extent in which process parameters influence each quality characteristic by using the comparability sequence with a large value of grey relational grade. Another two studies conducted by Fung et al. [21] and Yang [22] used the same procedure to optimize the processing parameters for multiple quality characteristics. The former focused on the concurrent improvement of yield stress and elongation of the PC/ABS blend, whereas the latter examined the effects of processing parameters on the mechanical and tribological properties of PC composites, including ultimate stress, surface roughness, and friction coefficient.

Another technique that can be applied with the Taguchi method in addressing multiple quality characteristic problems is principal component analysis (PCA). By using PCA, a set of original responses is transformed into a set of uncorrelated components to find the optimal factor or level combination. PCA does nothing when responses are uncorrelated; thus, the best results are obtained when responses or quality characteristics are highly correlated (either positively or negatively) [23]. The application of PCA involves a series of steps that are capable of solving the weakness of the standalone Taguchi method, which requires engineering judgment to handle multiple quality characteristics because the judgment of an engineer increases uncertainty during the decision-making process [24]. Fung and Kang [25] applied PCA to the Taguchi method to improve friction properties, including friction coefficients and surface roughness, in different sliding directions (P-type and AP-type). The authors extracted the principal components and the coefficient of determination to establish a comprehensive index and obtain the final optimal parameter setting.

Although both techniques are widely integrated with the Taguchi method to overcome multiple quality characteristic problems, both integration techniques have several limitations. In combining the Taguchi method and GRA, a problem arises when calculating the value of the grey relational grade in GRA. An engineering judgment or subjective estimation is required to determine the weighting values for each quality characteristic, thus resulting in an increase in uncertainty during the decision-making process. This approach cannot objectively reveal the relative importance of multiple quality characteristic performance. For the integration of the Taguchi method and PCA, the primary problem is the difficulty of interpretation because the original variables are substituted and the principal components are heavily affected by the scaling of the variables. In both methods, no scientific analysis has been performed in terms of performance under optimal process conditions to verify the accuracy of the optimization results. Therefore, the effectiveness and reliability of the integration of the Taguchi method with GRA or PCA alone remain uncertain. Further validation experiments on the optimization results are needed to prove the effectiveness of the integrated approach.

This study develops a hybrid optimization method by integrating the robust parameter design of Taguchi, GRA, and PCA to solve problems with multiple quality characteristics. An injection-moulded plastic gear is used to demonstrate the efficiency and validity of the proposed hybrid optimization method in controlling all influential injection moulding processing parameters during plastic gear manufacturing. By focusing on minimizing the shrinkage behaviour in the tooth thickness, addendum circle, and dedendum circle of moulded gear, the optimal combination of four process parameters, namely, melt temperature, packing pressure, packing time, and cooling time, at three different levels is determined by using the proposed hybrid optimization method.

\section{Taguchi/GRA/PCA Hybrid Method for the Optimization of Injection Moulding Process Parameters}

2.1. Taguchi Method. The Taguchi method is used to design experiments based on the orthogonal arrays (OAs). Taguchi OAs are highly fractional orthogonal designs that can be used 
to study the whole parameter space with a small number of experiments. In analyzing the results, the Taguchi method uses a statistical measure of performance known as signal-tonoise $(\mathrm{S} / \mathrm{N})$ ratio. The $\mathrm{S} / \mathrm{N}$ ratio is a measure of performance to develop products or processes that are insensitive to noise factors in a controlled manner [26]. Noise factors are uncontrollable factors that influence product or process uncertainty. These factors include humidity and weather. Depending on the objective, three different methods can be used to calculate the $\mathrm{S} / \mathrm{N}$ ratio in the Taguchi method:

(1) smaller-the-better quality characteristic:

$$
\eta_{i j}=-10 \log \left(\frac{1}{n} \sum_{j=1}^{n} y_{i j}^{2}\right)
$$

(2) bigger-the-better quality characteristic:

$$
\eta_{i j}=-10 \log \left(\frac{1}{n} \sum_{j=1}^{n} \frac{1}{y_{i j}^{2}}\right)
$$

(3) nominal-the-better quality characteristic:

$$
\eta_{i j}=-10 \log \left(\frac{1}{n s} \sum_{j=1}^{n} y_{i j}^{2}\right)
$$

where $y_{i j}$ is the $i$ th test at the $j$ th trial, $n$ is the total number of tests, and $s$ is the standard deviation.

2.2. GRA. In the analysis of the processing parameters of the plastic gear in the case study, an appropriate mathematic model is established to study the relationship between target values and the quality characteristics of the plastic gear obtained from the experiment. The primary concern is to analyze the differences among the quality characteristics of plastic gear because of various processing parameters and to understand the relationship between quality characteristics and target values. GRA is a method that measures the correlation degree among factors based on the similarity or difference among factors. GRA is characterized by small data requirements and multifactor analysis. The procedure of the GRA is presented below.

Grey relational generation involves data preprocessing and calculation according to the quality characteristics. The computing method of the grey relational generation is as follows.

(1) The-larger-the-better (the higher the target value, the better):

$$
x_{i}^{*}(k)=\frac{x_{i}^{(O)}(k)-\min x_{i}^{(O)}(k)}{\max x_{i}^{(O)}(k)-\min x_{i}^{(O)}(k)} .
$$

(2) The-smaller-the-better (the smaller the target value, the better):

$$
x_{i}^{*}(k)=\frac{\max x_{i}^{(O)}(k)-x_{i}^{(O)}(k)}{\max x_{i}^{(O)}(k)-\min x_{i}^{(O)}(k)} .
$$

(3) The-nominal-the-better characteristic (if the target is a specific value, set the target value as $\mathrm{OB}$ ):

$$
x_{i}^{*}(k)=1-\frac{\left|x_{i}^{(\mathrm{O})}(k)-\mathrm{OB}\right|}{\max \left\{\max x_{i}^{(\mathrm{O})}(k)-\mathrm{OB}, \mathrm{OB}-\min x_{i}^{(\mathrm{O})}(k)\right\}} .
$$

$x_{i}^{(O)}(k)$ is the measurement of the quality characteristic, $\max x_{i}^{(O)}(k)$ is the largest value of $x_{i}^{(O)}(k)$, and $\min x_{i}^{(O)}(k)$ is the smallest value of $x_{i}^{(O)}(k)$.

We determine the difference sequence $\Delta_{0 i}(k)$ and the minimum value $\Delta_{\min }$ and maximum value $\Delta_{\max }$ in the difference sequence, including the parameter values required to set the reference sequence:

$$
\begin{gathered}
\Delta_{0 i}(k)=\left|x_{0}^{*}(k)-x_{i}^{*}(k)\right|, \\
\Delta_{\max }=\max _{\forall j \in i} \max _{\forall k}\left|x_{0}^{*}(k)-x_{j}^{*}(k)\right|, \\
\Delta_{\min }=\min _{\forall j \in i} \min _{\forall k}\left|x_{0}^{*}(k)-x_{j}^{*}(k)\right| .
\end{gathered}
$$

We set the identification coefficient $Z$, which generally has a value of 0.5 .

After the data preprocessing, a grey relational coefficient is calculated to express the relationship between the ideal and actual normalized experimental results. The grey relational coefficient can be expressed as follows:

$$
\begin{aligned}
& \varepsilon_{i(k)}(k)=\frac{\Delta_{\min }+\psi \Delta_{\max }}{\Delta_{0 i}+\psi \Delta_{\max }}, \\
& 0<\varepsilon\left[x_{0}^{*}(k), x_{i}^{*}(k)\right] \leq 1 .
\end{aligned}
$$

The average of the grey relational coefficient is then calculated to obtain the grey relational grade. The grey relational grade is defined as follows:

$$
\gamma_{i}=\frac{1}{n} \sum_{k=1}^{n} \varepsilon_{i}(k)
$$

However, the effect of each factor on the system is not exactly the same in real applications. Thus, (9) can be modified as follows:

$$
\gamma_{i}=\sum_{k=1}^{n} w_{k} \cdot \varepsilon_{i}(k),
$$

where $w_{k}$ represents the normalized weighting value of factor $k$. Given the same weights, (9) and (10) are equal. In GRA, the grey relational grade is used to show the relationship among sequences. If two sequences are identical, the value of the grey relational grade is equal to one. The grey relational grade also indicates the degree of influence that the comparability sequence can exert over the reference sequence. Therefore, if a particular comparability sequence is more important than the other comparability sequences to the reference sequence, the grey relational grade for that comparability sequence and reference sequence will be higher than other grey relational grades [27]. In this study, the corresponding weighting values $w_{k}$ are obtained from PCA. 
2.3. PCA. PCA was developed by Pearson [28] and Hotelling [29]. This approach explains the structure of variancecovariance by the linear combinations of each quality characteristic. The procedures are described as follows.

(1) Original Multiple Quality Characteristics Array. Consider

$$
\begin{gathered}
x_{i}(j), \quad i=1,2, \ldots, m, j=1,2, \ldots, n \\
x_{i}=\left[\begin{array}{cccccc}
x_{1}(1) & x_{1}(2) & x_{1}(3) & \cdots & \cdots & x_{1}(n) \\
x_{2}(1) & x_{2}(2) & x_{2}(3) & \cdots & \cdots & x_{2}(n) \\
\vdots & \vdots & \vdots & \ldots & \ldots & \vdots \\
x_{m}(1) & x_{m}(2) & x_{m}(3) & \cdots & \cdots & x_{m}(n)
\end{array}\right],
\end{gathered}
$$

where $m$ is the number of experiments and $n$ is the number of quality characteristics. In this paper, $x$ is the grey relational coefficient of each quality characteristic and $m=9$ and $n=3$.

(2) Correlation Coefficient Array. The correlation coefficient array is evaluated as follows:

$$
\begin{array}{r}
R_{j l}=\left(\frac{\operatorname{Cov}\left(x_{i}(j), x_{i}(l)\right)}{\sigma_{x i}(j) X \sigma_{x j}(l)}\right), \quad j=1,2,3, \ldots, n \\
\quad l=1,2,3, \ldots, n
\end{array}
$$

where $\operatorname{Cov}\left(x_{i}(j), x_{i}(l)\right)$ are the covariance of sequences $x_{i}(j)$ and $x_{i}(l)$, respectively; $\sigma_{x i}(j)$ is the standard deviation of sequence $x_{i}(j) ; \sigma_{x j}(l)$ is the standard deviation of sequence $x_{i}(l)$.

(3) Determining the Eigenvalues and Eigenvectors. The eigenvalues and eigenvectors are determined from the correlation coefficient array

$$
\left(R-\lambda_{k} I_{m}\right) V_{i k}=0
$$

where $\lambda_{k}$ is an eigenvalue, $\sum_{k=1}^{n} \lambda_{k}=n$, and $k=1,2, \ldots, n$; $V_{i k}=\left[a_{k 1}, a_{k 2}, \ldots, a_{k n}\right]^{T}$ correspond to eigenvalue $\lambda_{k}$.

(4) Principal Components. The uncorrelated principal component is formulated as follows:

$$
Y_{m k}=\sum_{i=1}^{n} X_{m}(i) \cdot V_{i k},
$$

where $Y_{m 1}$ is the first principal component, $Y_{m 2}$ is the second principal component, and so on. The entire technical line of the hybrid Taguchi/GRA/PCA process optimization method for plastic injection moulding is summarized and illustrated in Figure 1.

\section{Implementation of the Proposed Hybrid Taguchi/GRA/PCA Optimization Procedures for Plastic Gear}

3.1. Determination of Quality Characteristics. In this paper, a plastic gear is used to demonstrate the efficiency and
TABLE 1: General properties of PP.

\begin{tabular}{lc}
\hline Properties & \\
\hline Density $\left(\mathrm{g} / \mathrm{cm}^{3}\right)$ & 0.90 to 0.91 \\
Raw density $\left(\mathrm{g} / \mathrm{cm}^{3}\right)$ & 0.805 \\
Melt flow index $(\mathrm{g} / 10 \mathrm{~min})$ & 10.78 \\
Modulus of elasticity $(\mathrm{MPa})$ & 4100 \\
Charpy impact toughness $\left(\mathrm{kJ} / \mathrm{m}^{2}\right)$ & 1.4 to 1.8 \\
\hline
\end{tabular}

validity of the proposed hybrid optimization method. With the capability to run without lubrication and corrosion, plastic gears have been widely used in the automotive industry, office machines, household utensils, food and textile machinery, and a host of other applications [30]. Plastic-moulded gears offer some material properties that are not achievable with metal-based gears, including unique advantages in weight, noise, modulus, self-lubrication, chemical resistance, and low cost. However, the practicability of injection moulding in producing low-cost plastic-moulded gears remains restricted by the occurrence of shrinkage in the final parts. As one of the most common and prominent defects of plastic, severe shrinkage leads to the deflection or warpage of the moulded part and negatively affects the dimensional stability and accuracy of the involute profile, concentricity, roundness, tooth spacing uniformity, and gear size. Sever shrinkage defect is often forgotten and regarded lightly in many works related to plastic-moulded gears. However, this defect critically affects the quality of the final moulded gear, noise, and vibration and shortens the service life of the gear because of different damage mechanisms, such as tooth fatigue, creep, excessive wear, and plastic deformation. Hence, shrinkage minimization is the optimization objective of this paper. This paper focuses on the optimization of processing parameters via the integration of the Taguchi/GRA/PCA to minimize the shrinkage behaviour of plastic injection-moulded gears. To inspect shrinkage behaviour on the dimensional stability of the moulded gear, three quality characteristics are selected: tooth thickness, addendum circle, and dedendum circle.

3.2. Selection of Taguchi OA. In this study, the crystalline thermoplastic polypropylene (PP) is specified for the gear. The PP used in this study is obtained from Propylene Malaysia Sdn. Bhd., Malaysia. The general properties of PP are shown in Table 1. The spur gear design used is compliant with the American Gears Manufacturers Association standards. The detailed geometry and specifications of the gear are shown in Figure 2.

The PP gears are injected by using a Battenfeld TM750/210 injection moulding machine. The experiment is conducted with four controllable three-level processing parameters: melt temperature, packing pressure, packing time, and cooling time. Other processing parameters, such as mould temperature $\left(25^{\circ} \mathrm{C}\right)$, injection pressure $(80 \mathrm{bar})$, and stroke distance $(60 \mathrm{~mm})$, are kept constant during the experiment. The selected processing parameters and their levels are shown in Table 2 . The $\mathrm{L}_{9}\left(3^{4}\right)$ OA (Table 3 ) is conducted to study 


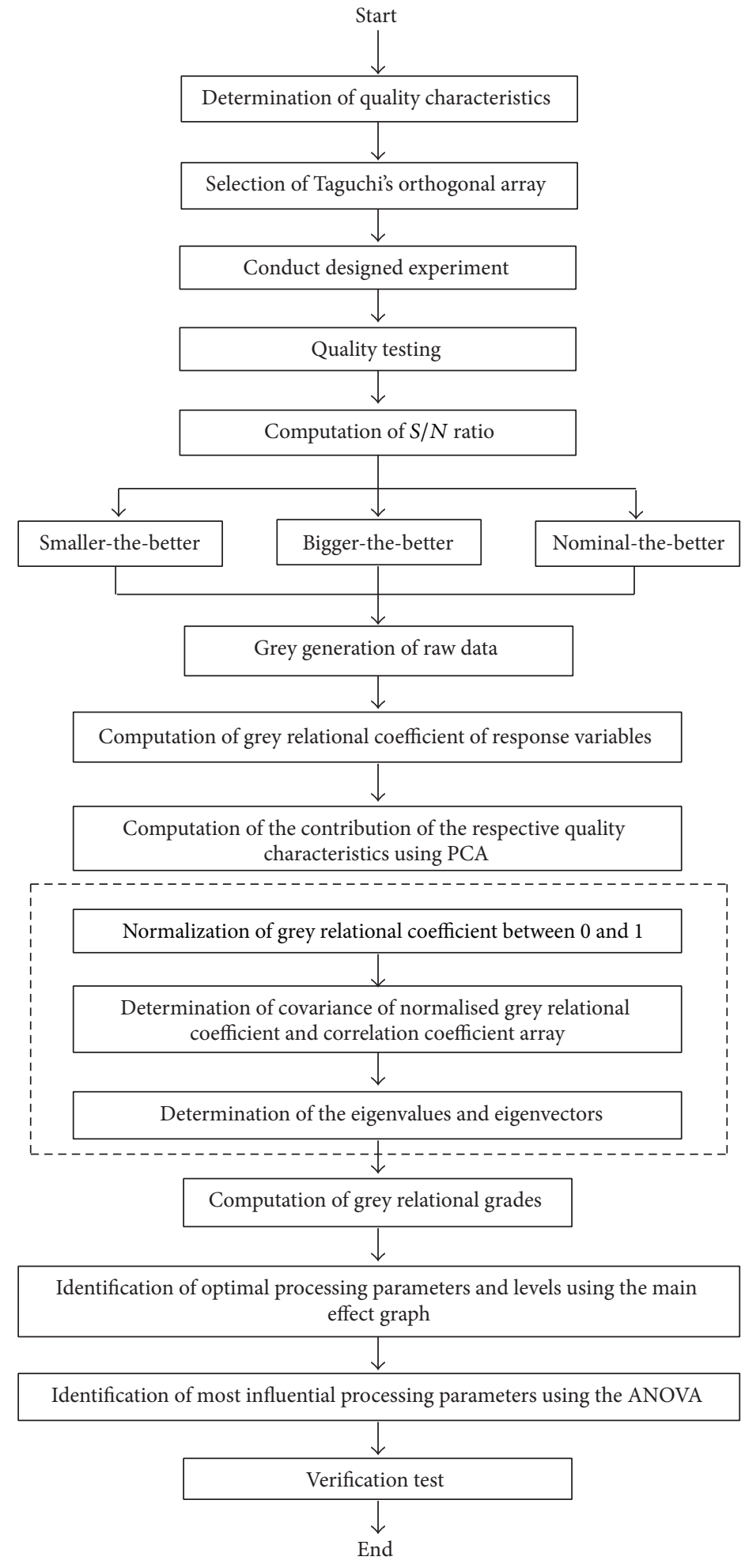

FIGURE 1: Technical line of hybrid Taguchi/GRA/PCA process optimization method.

the four processing parameters. Nine trials of PP gears with five repetitions are produced by using the OA.

3.3. Shrinkage Measurement. Rax Vision DC 3000 Mitutoyo profile projector is used to inspect the accuracy of the specific profile of the involute gear teeth after moulding. In this study, the profile projector is used to measure $2 \mathrm{D}$ tooth thickness, as well as addendum and dedendum circles, by using the coordinates of selected points along the gear profile. With large magnifications and micrometer readouts, 


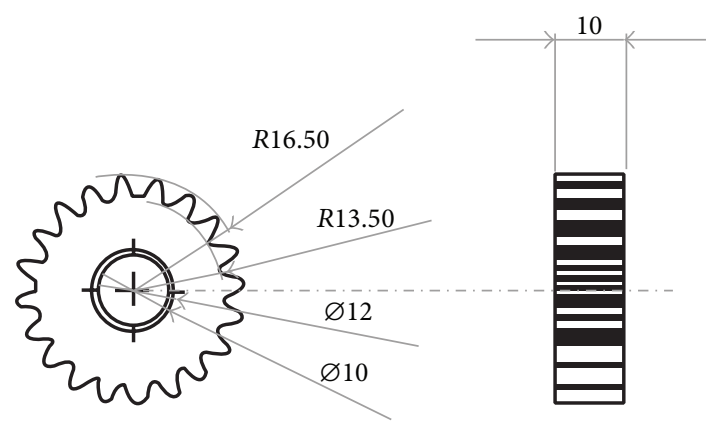

FIGURE 2: Geometry and specification of the spur gear: module = 1.5 ; pressure angle $=20^{\circ}$; number of teeth $=20$; face width $=10 \mathrm{~mm}$.

TABLE 2: Processing parameters and levels studied.

\begin{tabular}{lcccc}
\hline Column & Factors & Level 1 & Level 2 & Level 3 \\
\hline A & Melt temperature $\left({ }^{\circ} \mathrm{C}\right)$ & 200 & 220 & 240 \\
B & Packing pressure $(\%)$ & 60 & 80 & 100 \\
C & Packing time (s) & 5 & 10 & 15 \\
D & Cooling time (s) & 30 & 40 & 50 \\
\hline
\end{tabular}

TABLE 3: OA $L_{9}\left(3^{4}\right)$ of the experimental runs.

\begin{tabular}{lcccc}
\hline $\begin{array}{l}\text { Factors/trial } \\
\text { no. }\end{array}$ & $\begin{array}{c}\text { A } \\
\text { Melt } \\
\text { temperature } \\
\left({ }^{\circ} \mathrm{C}\right)\end{array}$ & $\begin{array}{c}\text { B } \\
\text { Packing } \\
\text { pressure } \\
(\%)\end{array}$ & $\begin{array}{c}\text { C } \\
\text { Packing } \\
\text { time }(\mathrm{s})\end{array}$ & $\begin{array}{c}\mathrm{D} \\
\text { Cooling } \\
\text { time }(\mathrm{s})\end{array}$ \\
\hline 1 & 200 & 60 & 5 & 30 \\
2 & 200 & 80 & 10 & 40 \\
3 & 200 & 100 & 15 & 50 \\
4 & 220 & 60 & 10 & 50 \\
5 & 220 & 80 & 15 & 30 \\
6 & 220 & 100 & 5 & 40 \\
7 & 240 & 60 & 15 & 40 \\
8 & 240 & 80 & 5 & 50 \\
9 & 240 & 100 & 10 & 30 \\
\hline
\end{tabular}

the profile projector can ensure fairly accurate measurements compared with a Vernier caliper and micrometer. In the process of addendum and dedendum circle measurement, 20 edge points of each tooth gear are set in the profile projector. To ensure the integrity of the comparison procedure, 5 injection-moulded gears from the same batch are measured to determine the repeatability of the part geometry. The relative shrinkage of the selected quality characteristics is calculated by using the following equation:

$$
S=\frac{\left(D-D_{m}\right)}{D_{m}}
$$

where $S$ is shrinkage, $D$ is the reading of the diameter measurement by using the profile projector, and $D_{m}$ is the mould dimension.
3.4. S/N Analysis. For constant processing parameters, the average value of five repeated results for shrinkage behaviour in tooth thickness, addendum circle, and dedendum circle is calculated and is considered the final result. In processing optimization, all the results of shrinkage behaviour in tooth thickness, addendum circle, and dedendum circle are transformed into $\mathrm{S} / \mathrm{N}$ ratio. The conversion of the results into $\mathrm{S} / \mathrm{N}$ ratio involves a series of calculations of the mean squared deviation. For this case, the smaller-the-better category is used to characterize the shrinkage behaviour of tooth thickness, addendum circle, and dedendum circle (see (1)). The final measured results and $\mathrm{S} / \mathrm{N}$ ratios for the three quality characteristics are shown in Table 4 .

3.5. Grey Generation of Raw Data. In the GRA, the experimental results for the $\mathrm{S} / \mathrm{N}$ ratios of shrinkage behaviour in tooth thickness, addendum circle, and dedendum circle in Table 4 are first normalized according to the-smaller-thebetter characteristic of the sequence by using (5). The values of tooth thickness, addendum circle, and dedendum circle are set as the reference sequence $x_{0}^{(O)}(k), k=1,2,3$ and the comparability sequences $x_{i}^{(O)}(k), i=1,2,3, \ldots, 9, k=$ $1,2,3$. Table 5 lists all the sequences after data preprocessing. According to Deng (1989) [19], a larger value of the normalized results corresponds to better performance and the maximum normalized results that are equal to one indicate the best performance.

According to Table 5 , the deviation sequences $\Delta_{01}(k)$ can be calculated as follows:

$$
\begin{aligned}
& \Delta_{01}(1)=\left|x_{0}^{*}(1)-x_{1}^{*}(1)\right|=|1.0000-0.0000|=1.0000, \\
& \Delta_{01}(2)=\left|x_{0}^{*}(2)-x_{1}^{*}(2)\right|=|1.0000-0.8743|=0.1257, \\
& \Delta_{01}(3)=\left|x_{0}^{*}(3)-x_{1}^{*}(3)\right|=|1.0000-0.9757|=0.0243 .
\end{aligned}
$$

Therefore, $\Delta_{01}=(1.0000,0.1257,0.0243)$.

The same calculating method is performed for $i=$ $1, \ldots, 9$, and the results of all $\Delta_{0 i}$ for $i=1, \ldots, 9$ are listed in Table 6. By investigating the data presented in Table 6 , $\Delta_{\max }(k)$ and $\Delta_{\min }(k)$ can be expressed as follows:

$$
\begin{aligned}
& \Delta_{\text {max }}=\Delta_{08}(1)=\Delta_{05}(2)=\Delta_{02}(3)=1.0000, \\
& \Delta_{\text {min }}=\Delta_{01}(1)=\Delta_{08}(2)=\Delta_{09}(3)=0.0000 .
\end{aligned}
$$

3.6. Computation of the Grey Relational Coefficient of Response Variables. The grey relational coefficients for each quality characteristic have been calculated by substituting the distinguishing coefficient $\psi=0.5$ by using (8). Examples on grey relational coefficient $\varepsilon_{1(k)}$ are provided as follows:

$$
\begin{aligned}
& \varepsilon_{1(1)}=\frac{0.0000+(0.5)(1.0000)}{1.0000+(0.5)(1.0000)}=0.3333, \\
& \varepsilon_{1(2)}=\frac{0.0000+(0.5)(1.0000)}{0.1257+(0.5)(1.0000)}=0.7991, \\
& \varepsilon_{1(3)}=\frac{0.0000+(0.5)(1.0000)}{0.0243+(0.5)(1.0000)}=0.9536 .
\end{aligned}
$$


TABLE 4: Average shrinkage and $\mathrm{S} / \mathrm{N}$ ratios for each trial.

\begin{tabular}{|c|c|c|c|c|c|c|}
\hline \multirow[b]{2}{*}{ Trials } & \multicolumn{3}{|c|}{ Average shrinkage } & \multicolumn{3}{|c|}{$\mathrm{S} / \mathrm{N}$ ratio } \\
\hline & $\begin{array}{l}\text { Tooth thickness } \\
(\mathrm{mm})\end{array}$ & $\begin{array}{l}\text { Addendum circle } \\
(\mathrm{mm})\end{array}$ & $\begin{array}{c}\text { Dedendum circle } \\
(\mathrm{mm})\end{array}$ & $\begin{array}{c}\text { Tooth thickness } \\
(\mathrm{dB})\end{array}$ & $\begin{array}{c}\text { Addendum circle } \\
(\mathrm{dB})\end{array}$ & $\begin{array}{c}\text { Dedendum circle } \\
(\mathrm{dB})\end{array}$ \\
\hline 1 & -0.0285 & -0.0211 & -0.0197 & 29.1568 & 33.5159 & 34.0801 \\
\hline 2 & -0.0542 & -0.0213 & -0.0198 & 25.0132 & 33.4284 & 34.0464 \\
\hline 3 & -0.0718 & -0.0202 & -0.0188 & 22.2234 & 33.8712 & 34.4891 \\
\hline 4 & -0.1067 & -0.0200 & -0.0196 & 19.2536 & 33.9651 & 34.1543 \\
\hline 5 & -0.1045 & -0.0215 & -0.0205 & 19.1704 & 33.3515 & 33.7506 \\
\hline 6 & -0.1174 & -0.0211 & -0.0192 & 18.4870 & 33.5269 & 34.3038 \\
\hline 7 & -0.0942 & -0.0202 & -0.0186 & 20.4134 & 33.8720 & 34.6027 \\
\hline 8 & -0.1298 & -0.0185 & -0.0174 & 17.6876 & 34.6592 & 35.1961 \\
\hline 9 & -0.0998 & -0.0197 & -0.0169 & 19.9179 & 34.0946 & 35.4325 \\
\hline
\end{tabular}

TABLE 5: Sequences after data preprocessing (grey generation).

\begin{tabular}{lccc}
\hline Trials & $\begin{array}{c}\text { Tooth } \\
\text { thickness }\end{array}$ & $\begin{array}{c}\text { Addendum } \\
\text { circle }\end{array}$ & $\begin{array}{c}\text { Dedendum } \\
\text { circle }\end{array}$ \\
\hline $\begin{array}{l}\text { Reference sequence } \\
\text { Comparability sequence }\end{array}$ & 1.0000 & 1.0000 & 1.0000 \\
1 & 0.0000 & 0.8743 & 0.9757 \\
2 & 0.3613 & 0.9412 & 1.0000 \\
3 & 0.6045 & 0.6026 & 0.6806 \\
4 & 0.8635 & 0.5308 & 0.9221 \\
5 & 0.8707 & 1.0000 & 1.2133 \\
6 & 0.9303 & 0.8659 & 0.8143 \\
7 & 0.7623 & 0.6020 & 0.5987 \\
8 & 1.0000 & 0.0000 & 0.1706 \\
9 & 0.8055 & 0.4317 & 0.0000 \\
\hline
\end{tabular}

TABLE 6: Deviation sequences.

\begin{tabular}{lccc}
\hline Deviation sequences & $\Delta_{01}$ & $\Delta_{02}$ & $\Delta_{03}$ \\
\hline Trial 1 & 1.0000 & 0.1257 & 0.0243 \\
Trial 2 & 0.6387 & 0.0588 & 0.0000 \\
Trial 3 & 0.3955 & 0.3974 & 0.3194 \\
Trial 4 & 0.1365 & 0.4692 & 0.0779 \\
Trial 5 & 0.1293 & 0.0000 & 0.2133 \\
Trial 6 & 0.0697 & 0.1341 & 0.1857 \\
Trial 7 & 0.2377 & 0.3980 & 0.4013 \\
Trial 8 & 0.0000 & 1.0000 & 0.8294 \\
Trial 9 & 0.1945 & 0.5683 & 1.0000 \\
\hline
\end{tabular}

Thus, $\varepsilon_{1(k)}=(0.3333,0.7991,0.9536), k=1,2,3$. A similar procedure is applied for $i=1, \ldots, 9$. Table 7 lists the grey relational coefficient for each trial of the $\mathrm{L}_{9} \mathrm{OA}$.

3.7. Computation of the Contribution of Respective Quality Characteristics by Using PCA. In optimizing a problem concerning multiple quality characteristics or performances, an engineering judgment or subjective estimation is needed to
TABLE 7: Calculated grey relational coefficient for nine comparability sequences.

\begin{tabular}{lccc}
\hline \multicolumn{3}{c}{ Grey relational coefficient } \\
Trials & $\begin{array}{c}\text { Tooth thickness } \\
(\mathrm{mm})\end{array}$ & $\begin{array}{c}\text { Addendum circle } \\
(\mathrm{mm})\end{array}$ & $\begin{array}{c}\text { Dedendum circle } \\
(\mathrm{mm})\end{array}$ \\
\hline 1 & 0.3333 & 0.7991 & 0.9536 \\
2 & 0.4391 & 0.8948 & 1.0000 \\
3 & 0.5584 & 0.5572 & 0.6102 \\
4 & 0.7855 & 0.5159 & 0.8652 \\
5 & 0.7946 & 1.0000 & 0.7009 \\
6 & 0.8777 & 0.7885 & 0.7291 \\
7 & 0.6778 & 0.5568 & 0.5547 \\
8 & 1.0000 & 0.3333 & 0.3761 \\
9 & 0.7200 & 0.4680 & 0.3333 \\
\hline
\end{tabular}

TABLE 8: Eigenvalues and explained variation for principal components.

\begin{tabular}{lcc}
\hline Principal component & Eigenvalue & Explained variation (\%) \\
\hline First & 2.1402 & 71.34 \\
Second & 0.5926 & 19.75 \\
Third & 0.2672 & 8.908 \\
\hline
\end{tabular}

determine the weighting values for each quality characteristic. The use of the conventional method to determine the values for each quality characteristics is heavily reliant on experience and trial-and-error, thus resulting in an increase in uncertainty during the decision-making process. To reveal the relative importance for each quality characteristic in GRA objectively, the PCA is introduced. The PCA is adopted to determine the corresponding weighting values for each quality characteristic.

The elements of the array for the multiple quality characteristics listed in Table 7 represent the grey relational coefficient of each quality characteristic. These data are used to evaluate the correlation coefficient matrix and to determine the corresponding eigenvalues from (13) (Table 8). The eigenvector corresponding to each eigenvalue is listed 
TABLE 9: Eigenvectors for principal components.

\begin{tabular}{lccc}
\hline $\begin{array}{l}\text { Quality } \\
\text { characteristic }\end{array}$ & $\begin{array}{c}\text { First principal } \\
\text { component }\end{array}$ & $\begin{array}{c}\text { Eigenvector } \\
\text { Second principal } \\
\text { component }\end{array}$ & $\begin{array}{c}\text { Third principal } \\
\text { component }\end{array}$ \\
\hline $\begin{array}{l}\text { Tooth } \\
\text { thickness }\end{array}$ & -0.5365 & 0.7716 & 0.3419 \\
$\begin{array}{l}\text { Addendum } \\
\text { circle }\end{array}$ & 0.5678 & 0.6297 & -0.5302 \\
$\begin{array}{l}\text { Dedendum } \\
\text { circle }\end{array}$ & 0.6244 & 0.0904 & 0.7759 \\
\hline
\end{tabular}

TABLE 10: Contribution of each individual quality characteristic for the principal component.

\begin{tabular}{lc}
\hline Quality characteristic & Contribution \\
\hline Tooth thickness & 0.2878 \\
Addendum circle & 0.3224 \\
Dedendum circle & 0.3898 \\
\hline
\end{tabular}

TABLE 11: Grey relational grade and its order.

\begin{tabular}{lcc}
\hline Trial & Grey relational grade & Order \\
\hline 1 & 0.7253 & 5 \\
2 & 0.8046 & 2 \\
3 & 0.5782 & 7 \\
4 & 0.7297 & 4 \\
5 & 0.8243 & 1 \\
6 & 0.7910 & 3 \\
7 & 0.5908 & 6 \\
8 & 0.5419 & 8 \\
9 & 0.4880 & 9 \\
\hline
\end{tabular}

in Table 9, and the square of the eigenvector can represent the contribution of the corresponding quality characteristic to the principal component. The contribution of shrinkage behaviour in the tooth thickness, addendum circle, and dedendum circle of the PP-moulded gear is shown in Table 10; these contributions are listed as $0.2878,0.3224$, and 0.3898 , respectively. Moreover, the variance contribution for the first principal component characterizing the three quality characteristics is as high as $71.34 \%$. Therefore, for this study, the squares of the respective eigenvectors are selected as the weighting values of the related quality characteristic. Coefficients $w_{1}, w_{2}$, and $w_{3}$ in (10) are set as $0.2878,0.3224$, and 0.3898 , respectively.

3.8. Computation Grey Relational Grades. On the basis of (10) and the data listed in Table 7 , the grey relational grades are calculated as follows:

$$
\begin{aligned}
\gamma_{1}= & (0.2878 \times 0.3333)+(0.3224 \times 0.7991) \\
+ & (0.3898 \times 0.9536)=0.7232
\end{aligned}
$$

By using the same procedure, the grey relational grade of the comparability sequence for $i=1-9$ can also be obtained and is presented in Table 11. The processing parameters were

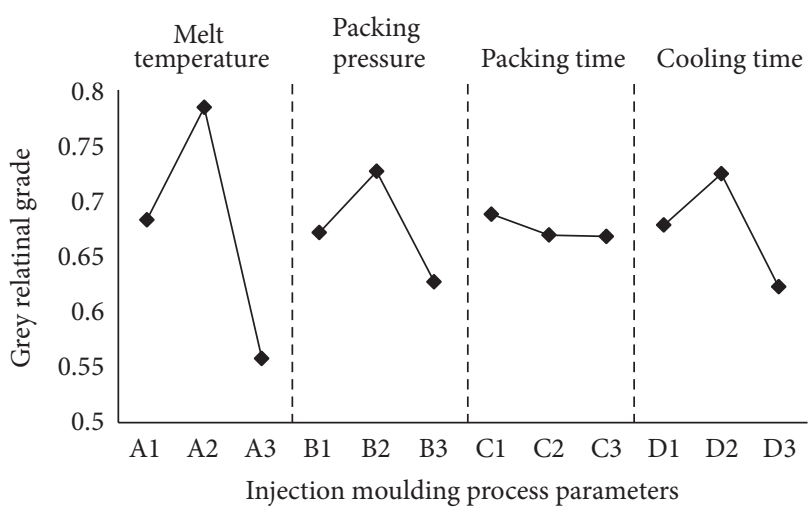

FIGURE 3: Effect of injection moulding parameter levels on multiple quality characteristics.

optimized with respect to a single grey relational grade rather than complicated multiple quality characteristics.

\section{Results and Discussion}

4.1. Optimal Combination of Injection Moulding Processing Parameters and Their Levels. To determine the optimal combination of injection moulding processing parameters for shrinkage behaviour in the tooth thickness, addendum circle, and dedendum circle of the studied moulded gear, the average grey relational grade for each injection moulding parameter level is calculated by employing the main effect analysis of the Taguchi method. This process is performed by sorting the grey relational grades corresponding to the levels of the injection moulding parameters in each column of the OA and then taking the average of parameters with the same levels. For instance, for factor A (Table 3), experiments 1, 2, and 3 are set to level 1 . Therefore, by using the data listed in Table 11, the average grey relational grade for $A_{1}$ can be calculated as follows:

$$
\bar{A}_{1}=\frac{(0.7253+0.8046+0.5782)}{3}=0.7027 .
$$

The average grey relational grade for $A_{2}$ and $A_{3}$ is calculated as follows:

$$
\begin{aligned}
& \bar{A}_{2}=\frac{(0.7297+0.8243+0.7910)}{3}=0.7817, \\
& \bar{A}_{3}=\frac{(0.5908+0.5419+0.4880)}{3}=0.5402 .
\end{aligned}
$$

By using a similar method, calculations are performed for each injection moulding parameter level, and the main effect analysis is constructed (Table 12 and Figure 3).

Considering that the grey relational grade represents the level of correlation between the reference and comparability sequences, a larger grey relational grade indicates that the comparability sequence exhibits a stronger correlation with the reference sequence. A larger grey relational grade results in better multiple quality characteristics. Figure 3 clearly shows that the multiple quality characteristics of the PPmoulded gear are significantly affected by the adjustments 
TABLE 12: Main effects table for grey relational grades.

\begin{tabular}{lcccc}
\hline Symbol & Process parameter & Level 1 & Level 2 & Level 3 \\
\hline A & Melt temperature $\left({ }^{\circ} \mathrm{C}\right)$ & 0.7027 & 0.7817 & 0.5403 \\
B & Packing pressure (\%) & 0.6819 & 0.7236 & 0.6191 \\
C & Packing time (s) & 0.6861 & 0.6741 & 0.6644 \\
D & Cooling time (s) & 0.6792 & 0.7288 & 0.6166 \\
\hline
\end{tabular}

TABLE 13: ANOVA table for the grey relational grade of nine comparability sequences.

\begin{tabular}{llcccc}
\hline Column & Parameters & DOF & $S$ & $V$ & $P$ \\
\hline A & Melt temperature $\left({ }^{\circ} \mathrm{C}\right)$ & 2 & 0.0909 & 0.0454 & 71.47 \\
B & Packing pressure $(\%)$ & 2 & 0.0166 & 0.0083 & 13.06 \\
C & Packing time (s) & 2 & 0.0007 & 0.0004 & 0.55 \\
D & Cooling time (s) & 2 & 0.0190 & 0.0095 & 14.92 \\
$\begin{array}{l}\text { All } \\
\text { others/error }\end{array}$ & & 0 & 0.0000 & 0.0000 & 0.00 \\
\hline Total & & 8 & 0.1272 & & 100.00 \\
\hline
\end{tabular}

of the processing parameters. The increment of melt temperature, packing pressure, and cooling time initially increases the grey relational grades, thus resulting in the reduction of shrinkage behaviour in the tooth thickness, addendum circle, and dedendum circle of the moulded gear. However, the relational grades for the three quality characteristics are lower when the melt temperature, packing pressure, and cooling time are $240^{\circ} \mathrm{C}, 100 \%$, and $50 \mathrm{~s}$, respectively. By contrast, the increment of packing time reduces the value of the grey relational grade, thus increasing the shrinkage behaviour in tooth thickness, addendum circle, and dedendum circle.

In this case, the best combination of processing parameters and levels can easily be obtained from the main effect analysis by selecting the level of each parameter with the highest grey relational grade. $A_{2}, B_{2}, C_{1}$, and $D_{2}$ show the largest value of grey relational grade for factors $\mathrm{A}, \mathrm{B}, \mathrm{C}$, and $\mathrm{D}$, respectively (Figure 3 ). Thus, the optimal parameter setting that statistically results in the minimum shrinkage behaviour in the tooth thickness, addendum circle, and dedendum circle of the PP-moulded gear is predicted to be $A_{2}, B_{2}, C_{1}$, and $\mathrm{D}_{2}$. The melt temperature is $220^{\circ} \mathrm{C}$, packing pressure is $80 \%$, packing time is $5 \mathrm{~s}$, and cooling time is $40 \mathrm{~s}$.

\subsection{Effects of Processing Parameters on Quality Characteristics.}

To examine the extent in which injection moulding parameters significantly influence the performance of moulded gear, ANOVA is performed on the Taguchi method for the grey relational grade of nine comparability sequences (Table 11). The computed quantity of degrees of freedom (DOF), sum of square $(S)$, variance $(V)$, and percentage contribution $(P)$ are presented in Table 13.

In this case, the percentage contribution of each processing parameter is directly calculated from $S$ because the DOF for the error term is equal to zero [31]. The significance of each processing parameter in the shrinkage behaviour in the tooth thickness, addendum circle, and dedendum circle of the moulded gear can be determined by the percentage
TABLE 14: Results of the verification test.

\begin{tabular}{lccc}
\hline $\begin{array}{l}\text { Verification } \\
\text { test }\end{array}$ & $\begin{array}{c}\text { Tooth thickness } \\
(\mathrm{mm})\end{array}$ & $\begin{array}{c}\text { Addendum } \\
\text { circle }(\mathrm{mm})\end{array}$ & $\begin{array}{c}\text { Dedendum } \\
\text { circle }(\mathrm{mm})\end{array}$ \\
\hline 1 & -0.0187 & -0.0194 & -0.0160 \\
2 & -0.0391 & -0.0186 & -0.0148 \\
3 & -0.0245 & -0.0165 & -0.0159 \\
4 & -0.0164 & -0.0194 & -0.0150 \\
5 & -0.0221 & -0.0162 & -0.0148 \\
\hline Average & -0.0180 & -0.0153 & -0.0242 \\
\hline
\end{tabular}

contribution. Roy [32] suggested an alternative by using the $10 \%$ rule; that is, a parameter is considered insignificant when its influence is less than $10 \%$ of the highest parameter influence. From the results of ANOVA in Table 13, melt temperature appears to be the most decisive processing parameter in reducing the shrinkage behaviour in the tooth thickness, addendum circle, and dedendum circle of the moulded gear with the highest percentage contribution of $71.47 \%$, thus outweighing the other process variables. The analysis also reveals that packing pressure and cooling time are significant because their percentages are more than $10 \%$ of the highest parameter influence (7.15\%). Cooling time and packing pressure achieve $14.92 \%$ and $13.06 \%$, respectively. Packing time results in only $0.55 \%$, which is significantly less than $10 \%$ of the highest parameter influence. In this case, the packing time is considered insignificant in the shrinkage behaviour of the tooth thickness, addendum circle, and dedendum circle of the moulded gear.

4.3. Verification Test. Once the optimal levels of the injection moulding process parameters are identified, the subsequent step is to verify the improvements in the quality characteristics by using this optimal combination. The verification test can be used to assess the accuracy of the proposed hybrid Taguchi/GRA/PCA optimization method. An experimental verification test is conducted by using the same procedures as previous runs under the optimal process conditions, namely, $A_{2}, B_{2}, C_{1}$, and $D_{2}$, to produce the plastic-moulded gear. Table 14 lists the results of five repetitions of the verification tests by using the optimal process conditions obtained by the proposed hybrid optimization method.

After optimization, the minimum shrinkage behaviour in tooth thickness, addendum circle, and dedendum circle is averaged as $1.8 \%, 1.53 \%$, and $2.42 \%$, respectively. The shrinkage behaviour for the three quality characteristics decreases with respect to those attained in the main experiment presented in Table 4.

\section{Conclusion}

In this study, a hybrid Taguchi/GRA/PCA optimization method for injection moulding process parameters has been developed systematically to overcome the shortcomings of individual methods in multiple quality characteristics problems. The problem that arises when calculating the weighting value for each quality characteristic in GRA has been 
addressed by integrating the PCA to determine the grey relational grades. Thus, the conventional approach of using engineering judgment or subjective estimation to determine the weighting values for each quality characteristics can be avoided. A plastic gear is employed in this study as a case study to demonstrate the efficiency and validity of the proposed hybrid optimization method in controlling all influential injection moulding processing parameters during plastic gear manufacturing. The shrinkage behaviour in tooth thickness, addendum circle, and dedendum circle is chosen as the optimization objectives. Through a series of analyses and optimizations of selected multiple quality characteristics for the case of a plastic gear, the minimum shrinkage behaviour in tooth thickness, addendum circle, and dedendum circle after optimization by the proposed hybrid optimization method is averaged as $1.8 \%, 1.53 \%$, and $2.42 \%$, respectively, which are less than the values in the main experiment.

\section{Conflict of Interests}

The authors would like to declare that all financial and material support for the conduct of this research and the preparation of this paper is clearly termed in the Acknowledgment and there will be no conflict of interests in relation to the financial gain subject to the publication of this paper.

\section{Acknowledgment}

The authors acknowledge the Research Grant provided by Universiti Sains Malaysia, Pulau Pinang, for funding the study that resulted in this paper.

\section{References}

[1] H. Kurtaran and T. Erzurumlu, "Efficient warpage optimization of thin shell plastic parts using response surface methodology and genetic algorithm," International Journal of Advanced Manufacturing Technology, vol. 27, no. 5-6, pp. 468-472, 2006.

[2] K.-T. Chiang and F.-P. Chang, "Analysis of shrinkage and warpage in an injection-molded part with a thin shell feature using the response surface methodology," International Journal of Advanced Manufacturing Technology, vol. 35, no. 5-6, pp. 468479, 2007.

[3] F. Shi, Z. L. Lou, J. G. Lu, and Y. Q. Zhang, "Optimisation of plastic injection moulding process with soft computing," International Journal of Advanced Manufacturing Technology, vol. 21, no. 9, pp. 656-661, 2003.

[4] J.-R. Shie, "Optimization of injection-molding process for mechanical properties of polypropylene components via a generalized regression neural network," Polymers for Advanced Technologies, vol. 19, no. 1, pp. 73-83, 2008.

[5] Y. C. Lam, L. Y. Zhai, K. Tai, and S. C. Fok, "An evolutionary approach for cooling system optimization in plastic injection moulding," International Journal of Production Research, vol. 42, no. 10, pp. 2047-2061, 2004.

[6] W.-C. Chen, G.-L. Fu, P.-H. Tai, and W.-J. Deng, "Process parameter optimization for MIMO plastic injection molding via soft computing," Expert Systems with Applications, vol. 36, no. 2, pp. 1114-1122, 2009.
[7] S. L. Mok, C. K. Kwong, and W. S. Lau, "Review of research in the determination of process parameters for plastic injection molding," Advances in Polymer Technology, vol. 18, no. 3, pp. 225-236, 1999.

[8] A. Mahfouz, S. A. Hassan, and A. Arisha, "Practical simulation application: evaluation of process control parameters in Twisted-Pair Cables manufacturing system," Simulation Modelling Practice and Theory, vol. 18, no. 5, pp. 471-482, 2010.

[9] H.-J. Shim and J.-K. Kim, "Cause of failure and optimization of a V-belt pulley considering fatigue life uncertainty in automotive applications," Engineering Failure Analysis, vol. 16, no. 6, pp. 1955-1963, 2009.

[10] N. M. Mehat and S. Kamaruddin, "Investigating the effects of injection molding parameters on the mechanical properties of recycled plastic parts using the Taguchi method," Materials and Manufacturing Processes, vol. 26, no. 2, pp. 202-209, 2011.

[11] A. Akbarzadeh, S. Kouravand, and B. M. Imani, "Robust design of a bimettallic micro thermal sensor using Taguchi method," Journal of Optimization Theory and Applications, vol. 157, no. 1, pp. 188-198, 2013.

[12] H. Li, Z. Guo, and D. Li, "Reducing the effects of weldlines on appearance of plastic products by Taguchi experimental method," International Journal of Advanced Manufacturing Technology, vol. 32, no. 9-10, pp. 927-931, 2007.

[13] C.-H. Wu and W.-J. Liang, "Effects of geometry and injectionmolding parameters on weld-line strength," Polymer Engineering and Science, vol. 45, no. 7, pp. 1021-1030, 2005.

[14] M.-C. Huang and C.-C. Tai, "Effective factors in the warpage problem of an injection-molded part with a thin shell feature," Journal of Materials Processing Technology, vol.110, no. 1, pp. 1-9, 2001.

[15] B. Ozcelik and T. Erzurumlu, "Comparison of the warpage optimization in the plastic injection molding using ANOVA, neural network model and genetic algorithm," Journal of Materials Processing Technology, vol. 171, no. 3, pp. 437-445, 2006.

[16] B. Ozcelik and I. Sonat, "Warpage and structural analysis of thin shell plastic in the plastic injection molding," Materials and Design, vol. 30, no. 2, pp. 367-375, 2009.

[17] H. Oktem, T. Erzurumlu, and I. Uzman, "Application of Taguchi optimization technique in determining plastic injection molding process parameters for a thin-shell part," Materials and Design, vol. 28, no. 4, pp. 1271-1278, 2007.

[18] S. J. Liao, D. Y. Chang, H. J. Chen et al., "Optimal process conditions of shrinkage and warpage of thin-wall parts," Polymer Engineering and Science, vol. 44, no. 5, pp. 917-928, 2004.

[19] J. Deng, "Introduction to grey system theory," Journal of Grey System, vol. 1, pp. 1-24, 1989.

[20] C.-P. Fung, "Manufacturing process optimization for wear property of fiber-reinforced polybutylene terephthalate composites with grey relational analysis," Wear, vol. 254, no. 3-4, pp. 298-306, 2003.

[21] C.-P. Fung, C.-H. Huang, and J.-L. Doong, "The study on the optimization of injection molding process parameters with gray relational analysis," Journal of Reinforced Plastics and Composites, vol. 22, no. 1, pp. 51-66, 2003.

[22] Y.-K. Yang, "Optimization of injection-molding process for mechanical and tribological properties of short glass fiber and polytetrafluoroethylene reinforced polycarbonate composites with grey relational analysis: a case study," Polymer, vol. 45, no. 7, pp. 769-777, 2006. 
[23] B. F. J. Manly, Multivariate Statistical Methods: A Primer, Chapman and Hall/CRC press, Boca Raton, Fla, USA, 3rd edition, 2005.

[24] H. C. Lio and Y. K. Chen, "Optimizing multi-response problem in the Taguchi method by DEA based ranking method," International Journal of Quality and Reliability Management, vol. 19, no. 7, pp. 825-837, 2002.

[25] C.-P. Fung and P.-C. Kang, "Multi-response optimization in friction properties of PBT composites using Taguchi method and principle component analysis," Journal of Materials Processing Technology, vol. 170, no. 3, pp. 602-610, 2005.

[26] Y. H. Chen, S. C. Tam, W. L. Chen, and H. Y. Zheng, "Application of the Taguchi method in the optimization of laser microengraving of photomasks," International Journal of Materials and Product Technology, vol. 11, no. 3-4, pp. 333-344, 1996.

[27] Y.-K. Yang, J.-R. Shie, and C.-H. Huang, "Optimization of dry machining parameters for high-purity graphite in end-milling process," Materials and Manufacturing Processes, vol. 21, no. 8, pp. 832-837, 2006.

[28] K. Pearson, "On lines and planes of closest fit to systems of points in space," Philosophical Magazine, vol. 6, no. 2, pp. 559$572,1901$.

[29] H. Hotelling, "Analysis of a complex of statistical variables into principal components," Journal of Educational Psychology, vol. 24, no. 6, pp. 417-441, 1933.

[30] K. Mao, W. Li, C. J. Hooke, and D. Walton, "Friction and wear behaviour of acetal and nylon gears," Wear, vol. 267, no. 1-4, pp. 639-645, 2009.

[31] S. M. Mousavi, S. A. Shojaosadati, J. Golestani, and F. Yazdian, "CFD simulation and optimization of effective parameters for biomass production in a horizontal tubular loop bioreactor," Chemical Engineering and Processing, vol. 49, no. 12, pp. 12491258, 2010.

[32] R. K. Roy, Design of Experiment Using the Taguchi Approach: 16 Steps to Product and Process Improvement, John Wiley and Sons, New York, NY, USA, 2001. 

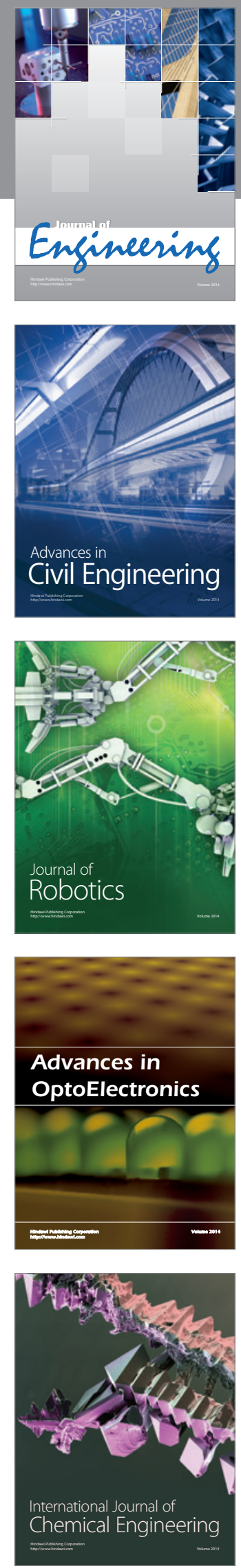

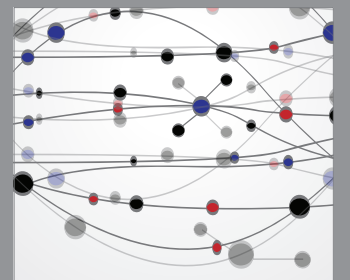

The Scientific World Journal
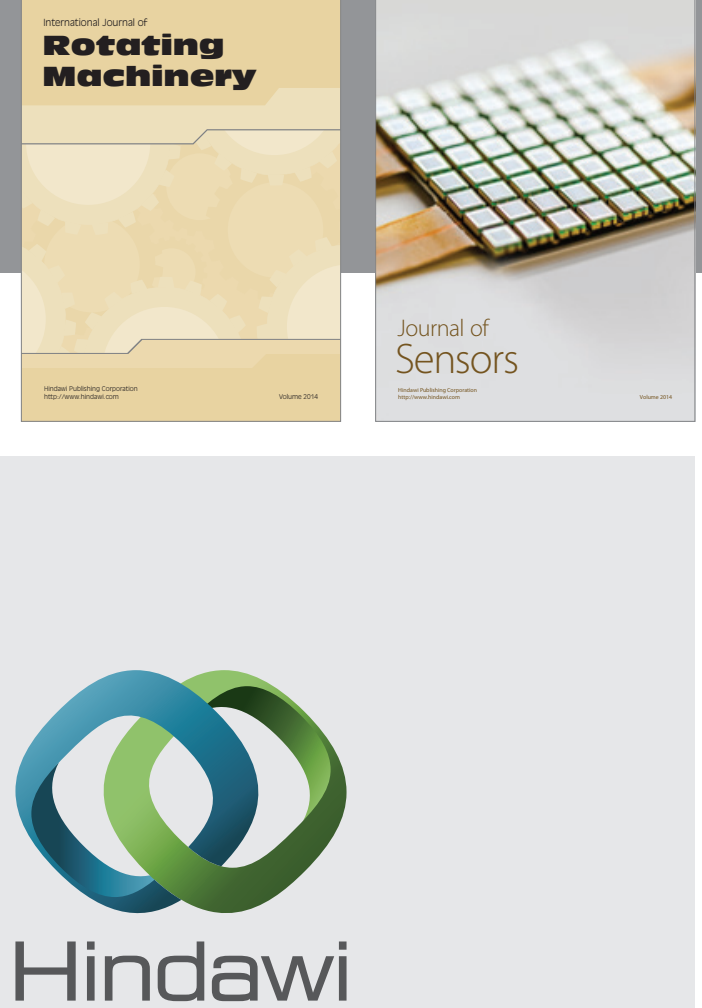

Submit your manuscripts at http://www.hindawi.com
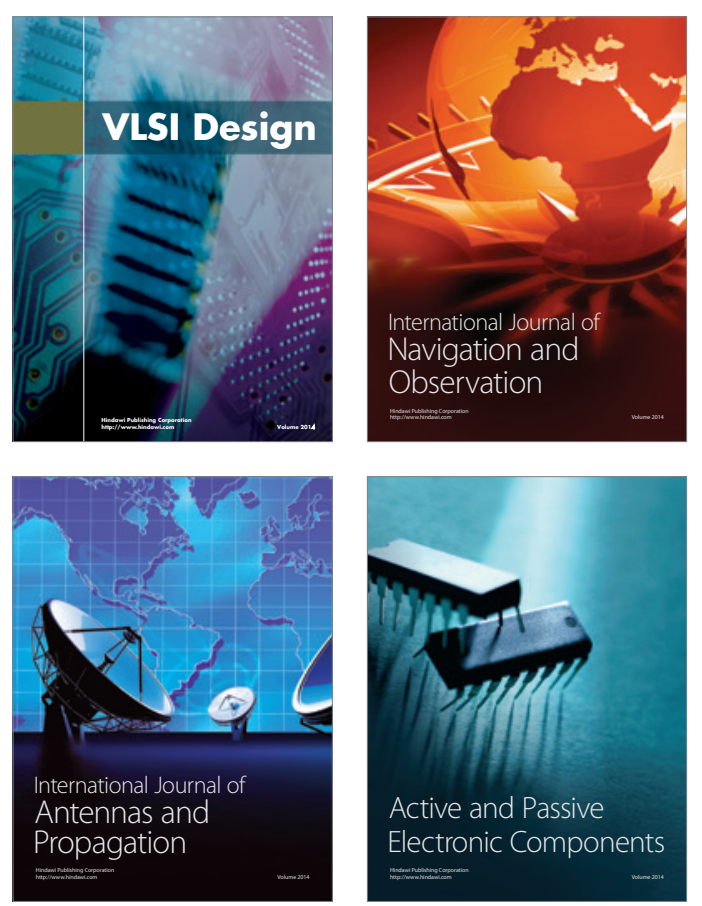
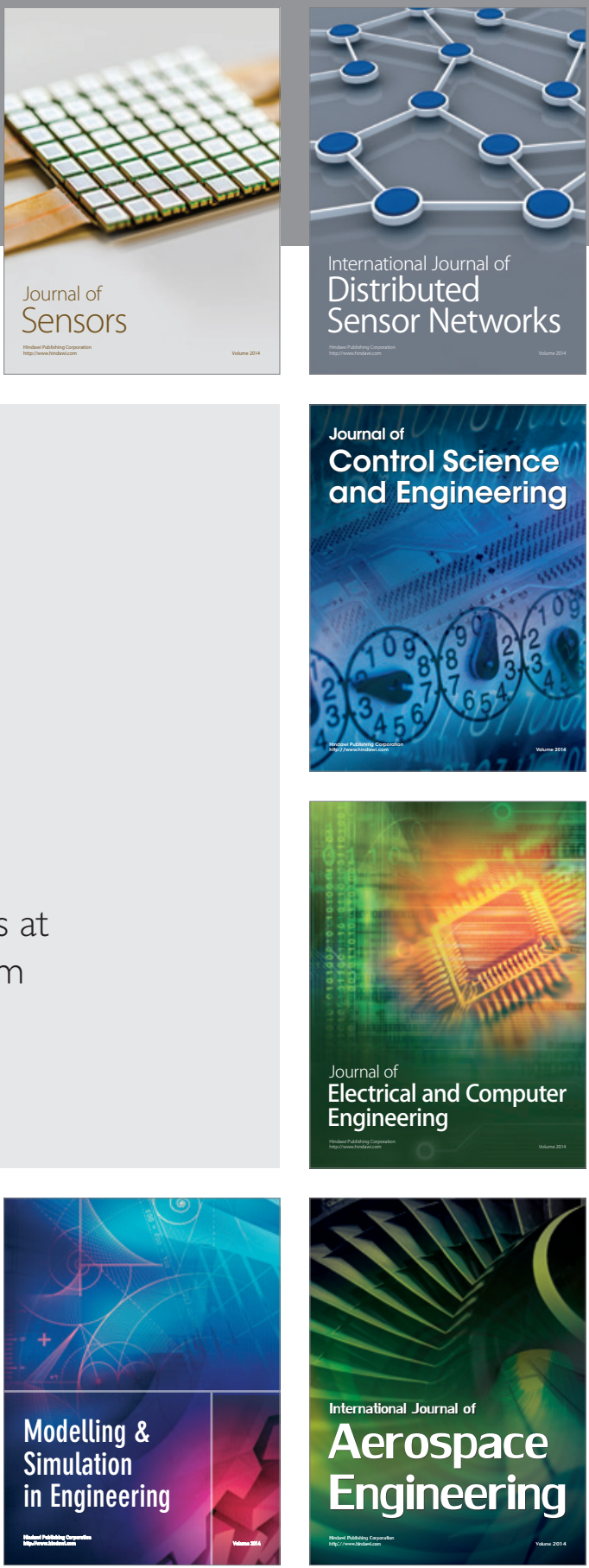

Journal of

Control Science

and Engineering
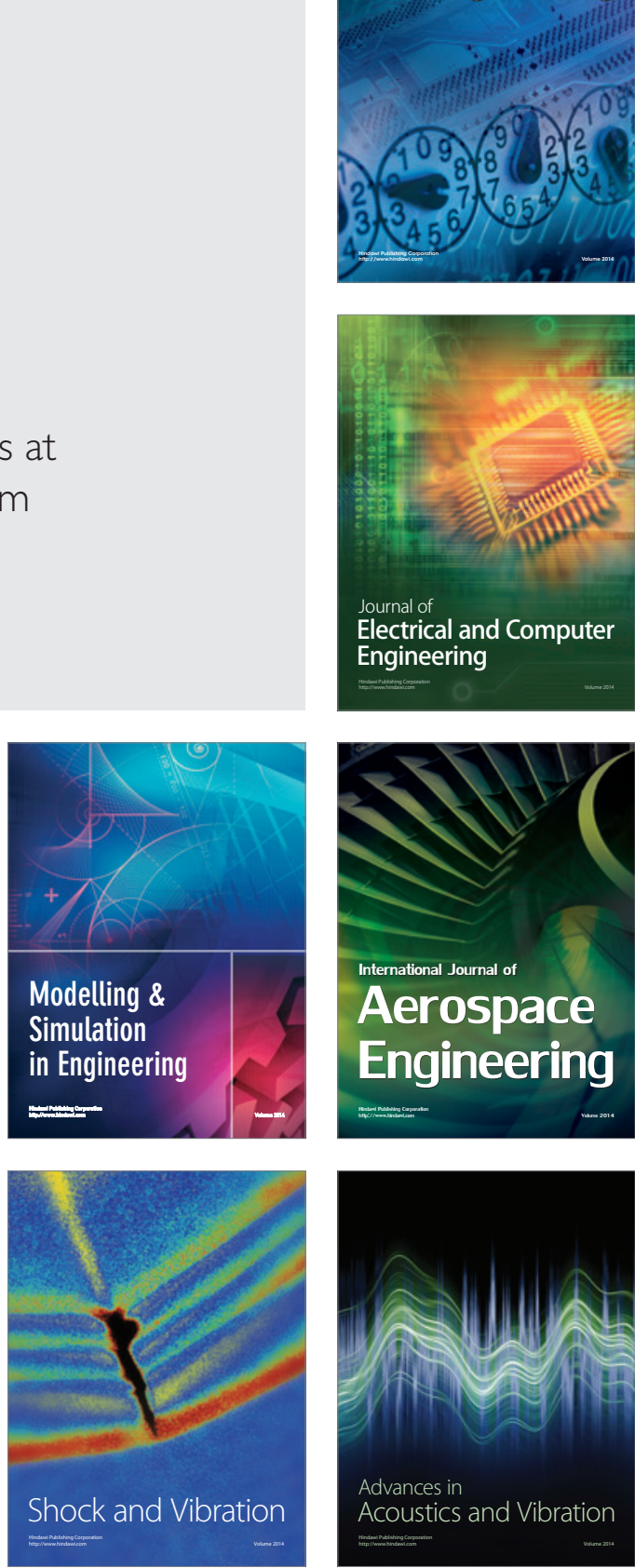